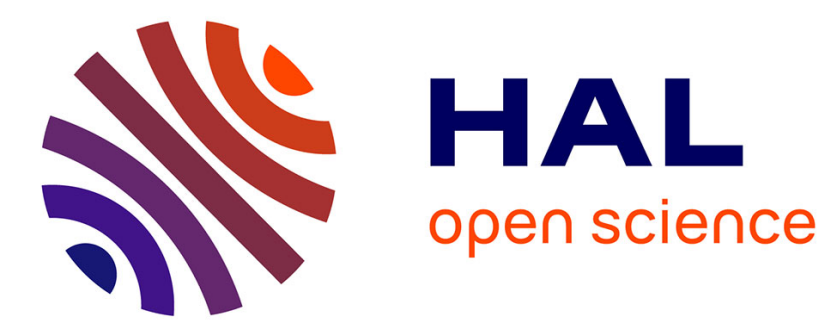

\title{
Cloud points in ionic surfactant solutions
}

J. Appell, G. Porte

\section{- To cite this version:}

J. Appell, G. Porte. Cloud points in ionic surfactant solutions. Journal de Physique Lettres, 1983, 44

(16), pp.689-695. 10.1051/jphyslet:019830044016068900 . jpa-00232251

\section{HAL Id: jpa-00232251 \\ https://hal.science/jpa-00232251}

Submitted on 1 Jan 1983

HAL is a multi-disciplinary open access archive for the deposit and dissemination of scientific research documents, whether they are published or not. The documents may come from teaching and research institutions in France or abroad, or from public or private research centers.
L'archive ouverte pluridisciplinaire HAL, est destinée au dépôt et à la diffusion de documents scientifiques de niveau recherche, publiés ou non, émanant des établissements d'enseignement et de recherche français ou étrangers, des laboratoires publics ou privés. 
Classification

Physics Abstracts

$64.60 \mathrm{~F}-64.60 \mathrm{H}-82.70$

\title{
Cloud points in ionic surfactant solutions
}

\author{
J. Appell \\ Laboratoire de Spectrométrie Rayleigh-Brillouin (*), Université des Sciences et Techniques du \\ Languedoc, 34060 Montpellier Cedex, France.
}

and G. Porte

Laboratoire de Minéralogie (**), G.D.P.C., Université des Sciences et Techniques du Languedoc, 34060 Montpellier Cedex, France.

(Reçu le 28 mars 1983, révisé le 20 mai, accepté le 24 juin 1983)

\begin{abstract}
Résumé. - On montre l'existence de températures critiques de démixtion dans des solutions aqueuses fortement salées de bromure, nitrate et chlorate de cétylpyridinium et de cétyltriméthylammonium. Le comportement critique des solutions est étudié à l'aide de la diffusion statique et dynamique de la lumière. Un aspect original de cette transition réside dans les valeurs inhabituellement grandes de la longueur de corrélation $\xi\left(>10^{3} \AA\right)$ plus de $10^{\circ} \mathrm{C}$ au-dessous de $T_{\mathrm{c}}$. Le phénomène de démixtion semble lié à l'existence de micelles allongées flexibles dans les solutions. On insiste sur les analogies avec les solutions critiques binaires polymère-solvant.

Abstract. - Experimental evidence is herein given of lower critical solution temperatures in high salt aqueous solutions of cetylpyridinium and cetyltrimethylammonium bromide, nitrate and chlorate. The critical behaviour of the solutions is followed using static and dynamic light scattering. The unique feature of this transition lies in the unusually large values of the correlation length $\xi\left(>10^{3} \AA\right)$ more than $10^{\circ} \mathrm{C}$ below the critical temperature. The occurrence of the phase separation seems to be connected with the existence of giant rod-like flexible micelles in the solutions. The analogies with critical solutions of polymers are underlined.
\end{abstract}

\section{Introduction.}

The importance of critical behaviours in mixtures involving surfactants has become more and more apparent over the last few years. Critical points have been found in the complex phase diagrams of microemulsions (involving four or even five chemical components) [1-3] and also in much simpler (binary) systems such as aqueous solutions of non ionic surfactants [4]. The transition is often discussed in terms of a liquid-gas transition in a dispersion of more or less spherical droplets or micelles. However, little is known about the microscopic structure of these systems around the critical point.

(*) E.R.A. au CNRS No 460 .

(**) L.A. au CNRS No 233. 
In a previous study we showed that the addition of a moderate amount of certain salts (few $10^{-1} \mathrm{M}$ ) such as $\mathrm{NaBr}, \mathrm{NaNO}_{3}$ or $\mathrm{NaClO}_{3}$ to dilute solutions (few \% in weight) of classical surfactants such as cetylpyridinium bromide $\mathrm{CPBr}$ or cetyltrimethylammonium bromide $\mathrm{CTABr}$ led to the formation of giant undimensional flexible micelles [5]. In the present paper we show that with very high concentrations of the same salts (4-5 $\mathrm{M}$ typically) a separation into two isotropic micellar phases of distinct composition occurs when the temperature is raised. The salt concentration in both phases was found to be the same so that they differ only with respect to the surfactant concentration. Therefore, at a given salt concentration, the minimum point $P\left(C_{\mathrm{c}}, T_{\mathrm{c}}\right)$ of the coexistence curve (such as in Fig. 2) is a true critical point. Both static and dynamic light scattering are used to determine the critical behaviour of the solutions around this lower consolute point. The general features of the transition, together with the existence of giant unidimensional flexible micelles at moderate (few $10^{-1} \mathrm{M}$ ) salt concentrations [5], seem to preclude the idea of a liquid-gas transition between small spherical micelles. Rather they support a description of the present phase separation analoguous to the phase separation observed in the case of polymers in a poor solvent. This behaviour is like that of a Flory-Huggins polymer solution.

\section{Experimental.}

$\mathrm{CTABr}$ is from Merck (analysis grade) and used without further purification. CPBr is synthetized and purified as ir references $5 . \mathrm{CPClO}_{3}$ is obtained from $\mathrm{CPBr}$ by recrystallization in concentrated $\mathrm{NaClO}_{3}$ aqueous solution and the purification involves several recrystallizations in pure water

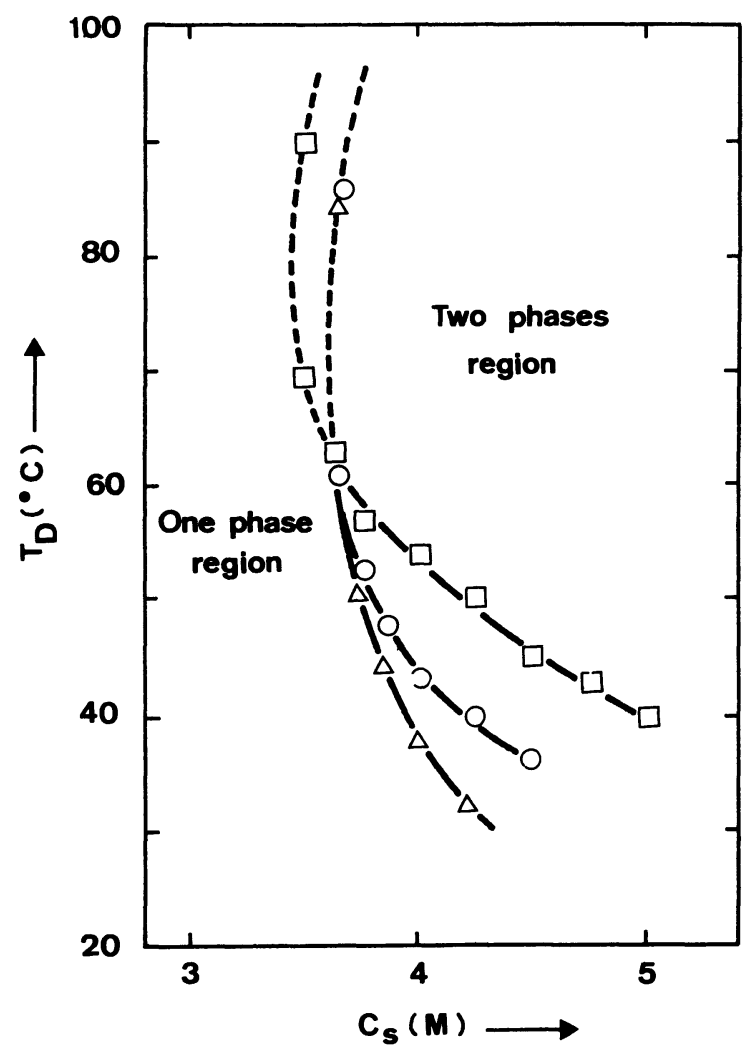

Fig. 1. - Coexistence curves for a $5 \mathrm{mg} / \mathrm{cm}^{3}$ surfactant solution as a function of the salt concentration. $\square: \mathrm{CPBr}+\mathrm{NaClO}_{3} ; \triangle: \mathrm{CPBr}+\mathrm{NaNO}_{3} ; \mathrm{O}: \mathrm{CTABr}+\mathrm{NaClO}_{3}$. 


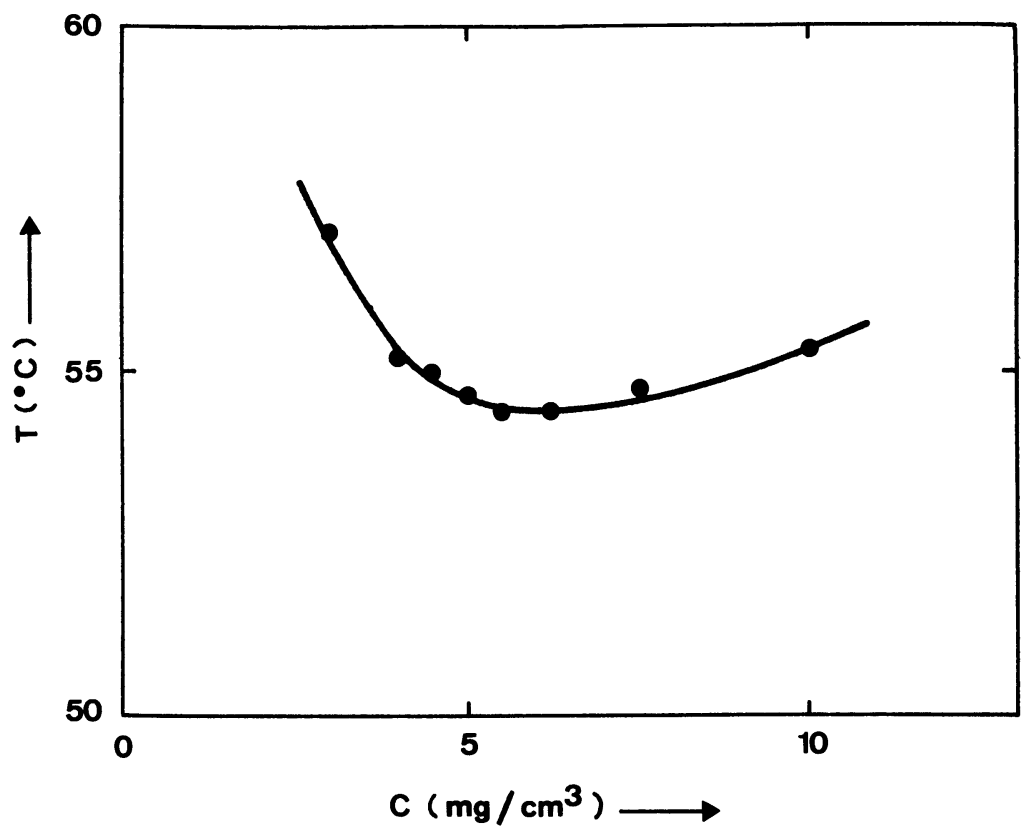

Fig. 2. - The coexistence curve for $\mathrm{CPClO}_{3}+\mathrm{NaClO}_{3} 4 \mathrm{M}$. The critical point is at $T_{\mathrm{c}}=54.4{ }^{\circ} \mathrm{C}$ and $C_{\mathrm{c}}=5.8 \mathrm{mg} / \mathrm{cm}^{3}$.

and dry acetone. The added salts $\mathrm{NaNO}_{3}, \mathrm{NaClO}_{3}$ were Merck analysis grade products and used without further purification. The solutions are prepared as followed : first the solvent (salt water) is prepared; then the proper weight of surfactant is dissolved in the proper volume of the total solution. The salt concentration $\left(C_{\mathrm{S}}\right)$ in $\mathrm{M}$ refers to the concentration of the solvent, and the surfactant concentration $(C)$ is given in $\mathrm{mg}$ of surfactant per $\mathrm{cm}^{3}$ of the solution. Most of the experiments are performed with solutions made with $\mathrm{CPBr}$ or $\mathrm{CTABr}$ even when the added salts are $\mathrm{NaNO}_{3}$ or $\mathrm{NaClO}_{3}$; we assume that the $\left(\mathrm{Br}^{-}\right)$concentration $\left(\mathrm{few} 10^{-3} \mathrm{M}\right)$ acts as an unimportant impurity compared to the concentration of the added salt (few M). However in order to obtain reliable absolute values for $T_{\mathrm{c}}$ and $C_{\mathrm{c}}$ in figure 2 this diagram was made using $\mathrm{CPClO}_{3}$ as the surfactant. The coexistence curves (Figs. 1 and 2) have been established using a water thermostat the temperature of which was regulated and measured to within $0.1{ }^{\circ} \mathrm{C}$. The viscosities are measured using a classical Ubbelohde viscometer. The static and dynamic light scattering measurements are performed using the standard apparatus described elsewhere [5]. The temperature of the scattering cell was regulated and measured to a precision of $0.1{ }^{\circ} \mathrm{C}$. However the housing of the thermostated scattering cell does not allow for a direct observation of the solution and $T_{\mathrm{c}}$ is determined to within $0.3^{\circ} \mathrm{C}$.

In figure 1 are drawn the variations of the temperature $T_{D}$ of the phase separation as a function of the salinity of the solvent for solutions with $5 \mathrm{mg} / \mathrm{cm}^{3} \mathrm{CPBr}$ or CTABr. Clearly, high salt concentrations $\left(C_{\mathrm{S}}\right)$ are required (of the order of $3.4 \mathrm{M}$ at least) for both $\mathrm{NaNO}_{3}$ and $\mathrm{NaClO}_{3}$ and for both surfactants. We verified that the separation of phases could also be obtained with $\mathrm{NaBr}$ as the added salt $\left(\mathrm{CPBr} 5 \mathrm{mg} / \mathrm{cm}^{3}, \mathrm{NaBr} 5.5 . \mathrm{M}\right)$ but $T_{\mathrm{D}}$ is very high $\left(>90^{\circ} \mathrm{C}\right)$ and we did not try to determine the curve $T_{\mathrm{D}}\left(C_{\mathrm{S}}\right)$ in this case. We also found that demixing was not observed with added salts (such as $\mathrm{NaCl}, \mathrm{NaBrO}_{3}, \mathrm{NaIO}_{3}$ ) which were formerly [6] found incapable of promoting micellar elongation at moderate concentrations. We thus guess that some connection 
exists between the presence of elongated flexible micelles and the occurrence of the phase separation. This connection is however not monotonic since at moderate salt concentration $C_{\mathrm{S}}$, $\mathrm{ClO}_{3}^{-}$is more effective in promoting micellar elongation than $\mathrm{NO}_{3}^{-}$while in figure 1 the $\mathrm{NO}_{3}^{-}$ mixtures demix at lower temperatures than the $\mathrm{ClO}_{3}^{-}$mixtures. In the high salt region $\left(C_{\mathrm{S}}>4 \mathrm{M}\right)$ the temperature of demixing decreases roughly linearly when $C_{\mathrm{s}}$ increases, and the solutions remain biphasic up to at least $100{ }^{\circ} \mathrm{C}$. But for $C_{\mathrm{s}}$ between $3.4 \mathrm{M}$ and $3.75 \mathrm{M}$ the slope of $T_{\mathrm{D}}\left(C_{\mathrm{s}}\right)$ is much steeper and the solutions become monophasic again at still higher temperatures (but, below $100^{\circ} \mathrm{C}$ ). This indicates that for a given value of $C_{\mathrm{S}}$ in this range, the coexistence curve $T_{\mathrm{D}}$ versus the surfactant concentration $(C)$ is a closed loop below $100^{\circ} \mathrm{C}$. This very interesting region of the phase diagram is under current study and will be discussed in a forthcoming article. The present letter is instead concerned with the high salt region $\left(C_{\mathrm{S}}=4 \mathrm{M}\right)$.

Figure 2 shows the coexistence curve for the mixture $\mathrm{CPClO}_{3}+$ aqueous solution of $\mathrm{NaClO}_{3}$ with $C_{\mathrm{s}}=4 \mathrm{M}$. The curve is quite asymmetric : the coordinates of the minimum point are $C_{\mathrm{c}} \simeq 5.8 \mathrm{mg} / \mathrm{cm}^{3}$ and $T_{\mathrm{c}} \simeq 54.4^{\circ} \mathrm{C}$. We have measured the salinity of both phases well above $T_{\mathrm{c}}$ : (we started with a homogeneous $7 \mathrm{mg} / \mathrm{cm}^{3}$ sample $\mathrm{CPClO}_{3}-4 \mathrm{MNaClO}_{3}$, we let it equilibrate for two days at $65.8^{\circ} \mathrm{C}\left(>T_{\mathrm{D}}^{3}\right)$, we took out given amounts of the two phases, in each of them we precipitated the surfactant by cooling, and after filtration and drying under vacuum for two days the remaining salt was weighed). The salt concentration was found to be the same in the two phases to within experimental errors $\left(\Delta C_{\mathrm{s}} / C_{\mathrm{s}}<2 \%\right)$. The solvent is thus the same (salt water $C_{\mathrm{s}}=4 \mathrm{M}$ ) in both phases and the mixtures can be treated as pseudo binary mixtures about the coexistence line : in particular the minimum point $P_{\mathrm{c}}\left(T_{\mathrm{c}}, C_{\mathrm{c}}\right)$ is a true critical point. It is therefore meaningful to treat the light scattering data about $p_{\mathrm{c}}$ according to what is classically expected about a critical point.

The light scattering experiments were performed according to preliminary results obtained prior to the determination of figure 2. The sample was a solution of $5 \mathrm{mg} / \mathrm{cm}^{3}$ of $\mathrm{CPBr}$ in a $4 \mathrm{M}$ aqueous solution of $\mathrm{NaClO}_{3}$. The discrepancy between this concentration and $C_{\mathrm{c}}\left(5.8 \mathrm{mg} / \mathrm{cm}^{3}\right)$ should not affect noticeably the critical behaviour. The angular anisotropy of the intensity of the scattered light was fitted to the Ornstein-Zernike law $\left(I=I_{0} /\left(1+q^{2} \xi^{2}\right)\right.$ where $q$ is the scattering wave vector and $\xi$ is the correlation length of the refractive index fluctuations) at different temperatures. The corresponding values of $\xi$, which are unusually large, are given as a function of $T-T_{\mathrm{c}}$ in table I together with the measured values of the shear viscosity of the solution $\eta$.

For the same set of temperatures the measured spectral widths $\Gamma(q)$ of the scattered light were scaled according to the now classical procedure [7] :

$$
\Gamma^{*}=\frac{\Gamma \times 6 \pi \eta}{k T \cdot q^{3}}
$$

In figure 3 the scaled linewidths $\Gamma^{*}(q \xi)$ are plotted against $q \xi$ in order to be compared to the universal law predicted by the mode-mode coupling theory [8]. Actually the distribution of the

Table $\mathrm{I}$. - The dependence of the viscosity $\eta$, the relative viscosity $\eta_{\mathrm{r}}=\eta / \eta_{\text {solvent }}$ and $\xi$ the correlation length upon $\left(T_{\mathrm{c}}^{*}-T\right)$.

$\begin{array}{cccc}T_{\mathrm{c}}-T \mathrm{~K} & \eta\left(10^{-} \text {poise }\right) & \eta_{\mathrm{r}} & \xi(\AA) \\ -1.6 & - & - & - \\ 3 & 1.65 & 2 & 4450 \\ 5.4 & 1.74 & 2 & 2900 \\ 7.6 & 1.88 & 2.2 & 2500 \\ 12.2 & 2.05 & 2.3 & 1750 \\ 17.7 & 2.4 & 2.4 & 1450 \\ & 3.0 & 2.8 & 1050\end{array}$




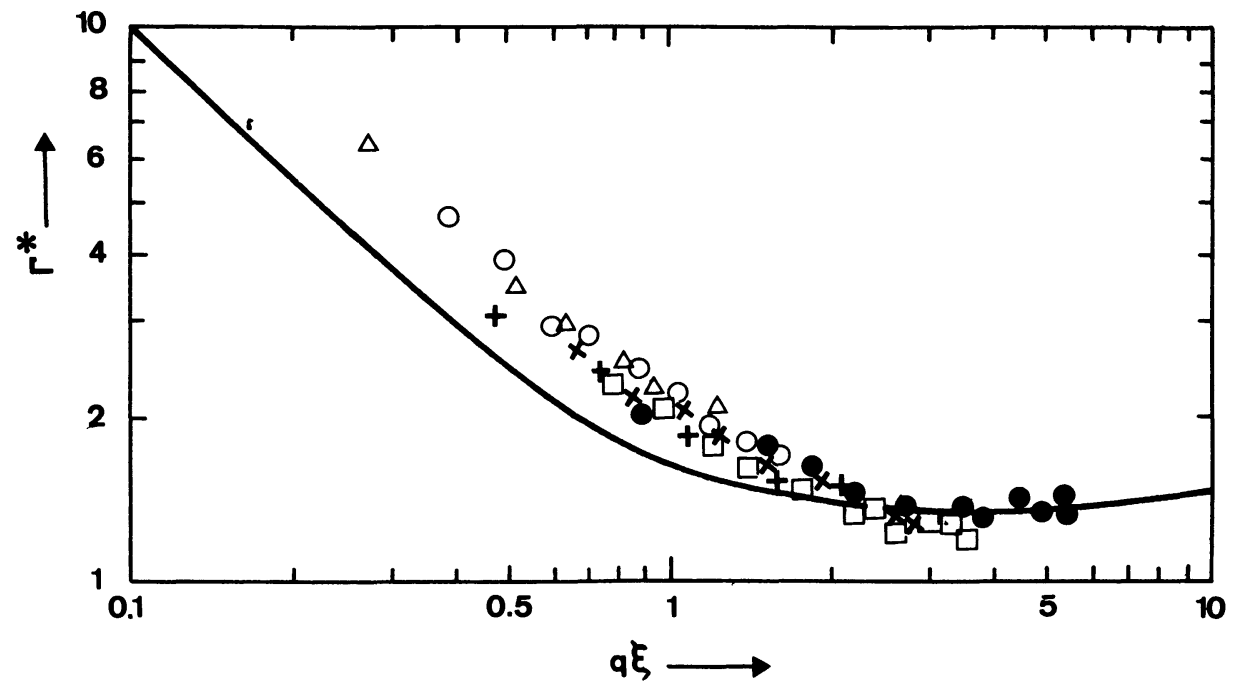

Fig. 3. - Scaled linewidth. $\Gamma^{*}$ as a function of $q \xi$ for $T\left({ }^{\circ} C\right)=37.5: \triangle ; 43: 0 ; 47:+; 50: \times ; 52:$ and $54: 0$. The solid line is the curve predicted by the modified mode-mode coupling theory [8].

experimental data roughly parallels the theoretical curve. The systematic excess discrepancy far from $T_{\mathrm{c}}$ probably indicates the existence of a non critical " background " contribution to the dynamics of the concentration fluctuations [9]. Such « background » contributions are well known to occur in the case of the liquid-gas transition in a simple fluid. It is known to vanish almost completely in the case of critical phase separation in classical binary mixtures of non macromolecular components. But it becomes noticeable again when one compound of the binary mixture is a long size flexible polymer [10]. In the critical region the correlation length is expected to scale according to the law :

$$
\xi=\xi_{0} \varepsilon^{-v},
$$

where $\varepsilon=\left|T-T_{\mathrm{c}}\right| / T_{\mathrm{c}}$. As mentioned before the accuracy of the determination of the temperature at which the phase separation occurs in the scattering cell is poor. However, since the critical range is extremely large $\left(\Delta T \sim 20^{\circ} \mathrm{C}\right)$ crude estimations were made of the values of $v$ and $\xi_{0}$ as shown in figure 4, giving $v \sim 0.6$ and $\xi_{0} \simeq 200 \AA$. The present approximate value of $v$ is not far from 0.63 as predicted by the three dimensional Ising model. The value of the prefactor $\xi_{0}$ is very much larger than what is measured in classical binary mixtures and also in " critical microemulsions " and non ionic surfactants aqueous critical mixtures.

\section{Discussion.}

The present transition shows some special characteristics that are not expected in the case of classical binary critical mixtures. In particular $C_{\mathrm{c}}$ the critical concentration is very low : about $5 \%$ by weight $\left(5.8 \mathrm{mg} / \mathrm{cm}^{3}\right)$. Also the coexistence curve in figure 2 has a strongly asymmetrical shape. These features have been discussed at length by Kjeclander [11] when dealing with similar cloud points in non ionic surfactants aqueous solutions. He showed that such a low value for $C_{\mathrm{c}}$ is inconsistent with the idea of a liquid-gas critical transition in a population of globular objects : the important point is that, at $C_{\mathrm{c}}$, the range of the interactions between the micellar objects must be of the same order of magnitude or larger than the mean intermicellar distance. Calculations [11] based on several short range interaction profiles between spherical objects inva- 


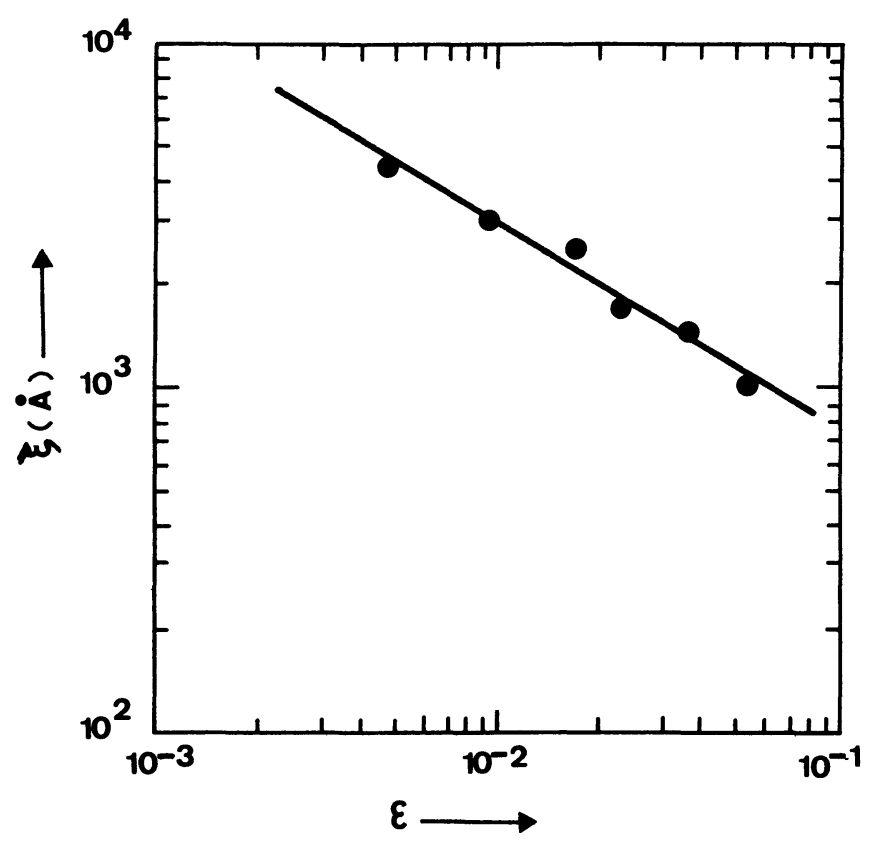

Fig. 4. - Correlation length $\xi$ as a function of $\varepsilon=\frac{\left|T-T_{\mathrm{c}}\right|}{T_{\mathrm{c}}}$. The solid line corresponds to $\xi=\xi_{0} \varepsilon^{-v}$ with $\xi_{0} \simeq 200 \AA$ and $v=0.6$.

riably led to values of $C_{\mathrm{c}}$ ranging between $7 \%$ and $20 \%$ in volume. Therefore, the very low value of $C_{\mathrm{c}}$ in the present case strongly suggests that the micelles have very anisotropic shapes when critical conditions are met.

On the other hand Anacker and Ghose [13] have shown that moderate addition of increasing amounts of $\mathrm{NaBr}, \mathrm{NaNO}_{3}$ or $\mathrm{NaClO}_{3}$ in the initially pure surfactant-water system promotes the rapid growth of the micelles. We have shown [5] further that these giant micelles are flexible cylinders. The diameter of the cross section of these cylindrical micelles is about $60 \AA$ and they are very flexible (persistence length of the order of $200 \AA$ ). The elongation process is a reversible phenomenon (reversible polymerization) and the equilibrium size distribution of the micelles depends on the temperature, the salt concentration and the surfactant concentration.

Because of the micellar interactions, it is difficult to determine the shape and structure of the micelles at very high salt concentrations around the critical conditions. However, according to the two preceding paragraphs, it is tempting to keep on with the same description for the micellar shape : the micelles are very much like Gaussian coils. And the present phases separation would then be very similar to the phase separation observed in the case of polymers in a poor solvent. Such a description would provide a natural explanation for the strong asymmetry of the coexistence curve. Another advantage of it is that it may also account for the unusually large values of $\xi$ around the critical point $(\xi$ is larger than the radius of gyration of individual coils when $T>\theta$ see reference 14 p. 212-213).

A puzzling point is however the unexpected behaviour of the viscosity in table $I$ : while the viscosity relative to the solvent $\left(\eta_{\mathrm{r}}\right)$ is expected to diverge weakly at $T_{\mathrm{c}}$, we instead measure monotonically decreasing values of $\eta_{r}$ This is possibly related to the fact that (in contrast to normal polymers) the mean size of the giant micelles decrease when $T$ increases [5] : the contribution of the mean micellar size variations to the variations of $\eta$ is perhaps large enough to hide the expected divergence. 
Apart from these questions about the critical behaviour of $\xi$ and $\eta$ arount $T_{\mathrm{c}}$, the difficult problem remains related to the balance between micelle-micelle and micelle-water interactions which is responsible for the observed phase separation. The fact that the separation occurs when the temperature rises usually indicates the existence of some strongly anisotropic (oriented) interaction between the two species of the binary mixture, (hydrogen bonds for instance) [15]. Intuitive explanations have been proposed on this basis in the case of non ionic surfactant aqueous solutions [4]. In the present case, where the micellar surface is strongly ionic the situation is more confused : in particular the specific rôle of the high added salt concentration is not understood.

\section{References}

[1] Cazabat, A. M., Chatenay, D., Langevin, D., Pouchelon, A., J. Physique Lett. 41 (1980) L-441. Cazabat, A. M., Langevin, D., Meunier, J., Pouchelon, A., J. Physique Lett. 43 (1982) L-89.

[2] Huang, J. S., Kim, M. W., Phys. Rev. Lett. 47 (1981) 1962.

[3] Dorshow, R., De Buzzaccarini, F., Bunton, C. A., Nicoli, D. F., Phys. Rev. Lett. 47 (1981) 1336.

[4] Corti, M., Degiorgio, V., Phys. Rev. Lett. 45 (1980) 1045.

Corti, M., Degiorgio, V., Zulauf, M., Phys. Rev. Lett. 48 (1982) 1617.

[5] Porte, G., Appell, J., Poggi, Y., J. Phys. Chem. 84 (1980) 3105.

APpell, J., Porte, G., J. Colloïd Interface Sci. 81 (1981) 85.

Porte, G., Appell, J., J. Phys. Chem. 85 (1981) 2511.

PORTE, G., APPELL, J., International Symposium on Surfactants in solutions (1982) Lund, Sweden.

[6] Anacker, E. W., Ghose, H. M., J. Am. Chem. Soc. 90 (1968) 3105.

[7] Stanley, H. E., Introduction to Phase Transitions and Critical Phenomena (Clarendon Press Oxford) 1971, p. 239.

[8] Kawasaki, K., Ann. Phys. 61 (1970) 1.

Kawasaki, K., Lo, S. M., Phys. Rev. Lett. 29 (1972) 48.

Lo, S. M., Kawasaki, K., Phys. Rev. A 5 (1972) 421.

Ibidem. A 8 (1973) 2176.

[9] Swinney, H. L., Henry, D. L., Phys. Rev. A 8 (1973) 2586.

[10] Chu, B., Lin, Y. H., Dinapoli, A., Nose, T., Kuwahara, N., Ferroelectrics 30 (1980) 255.

[11] KJellander, R., J. Chem. Soc. Faraday Trans. 278 (1982) 2025.

[12] Appell, J., Porte, G., Poggi, Y., J. Colloid Interface Sci. 87 (1982) 492.

[13] Anacker, E. W., Ghose, H. M., J. Am. Chem. Soc. 90 (1968) 3161.

[14] De Gennes, P. G., Scaling concepts in Polymer Physics (Cornell University Press, Ithaca and London).

[15] Goldstein, R. E., Walker, J. S., J. Chem. Phys. 78 (1983) 1493. 